\title{
Family Caregiver Identity: A Literature Review
}

By: Elise K. Eifert, Rebecca Adams, William Dudley \& Michael Perko

Eifert, E. K., Adams, R., Dudley, W., \& Perko, M. (2015). Family caregiver identity development: A literature review. American Journal of Health Education, 46(6), 357-367.

This is an Accepted Manuscript of an article published in the American Journal of Health Education online November 9, 2015, available online: http://www.tandfonline.com/doi/full/10.1080/19325037.2015.1099482

\section{Reprinted by permission of the Society of Health and Physical Educators, www.shapeamerica.org, (http://www.shapeamerica.org).}

\begin{abstract}
:
Background: Despite the multitude of available resources, family caregivers of those with chronic disease continually underutilize support services to cope with the demands of caregiving. Several studies have linked self-identification as a caregiver to the increased likelihood of support service use. Purpose: The present study reviewed the literature related to the development of family caregiver identity. Methods: After a systematic process to locate literature was completed, content analysis was conducted to determine major themes related to the development of caregiving identity. Results: Findings suggest that there are multiple factors related to the development of family caregiver identity, including role engulfment and reversal, loss of shared identity, family obligation and gender norming, extension of the former role, and development of a master identity. Discussion: Considering the role of identity in human behavior, health professionals can address the underutilization of support services by family caregivers of those with chronic disease by understanding the influences on the development of caregiver identity. Translation to Health Education Practice: This literature review will assist health educators in addressing the underutilization of support services by family caregivers of those with chronic disease.
\end{abstract}

Keywords: family caregivers | support services |identity

\section{Article:}

\section{Background}

As the aging population increases, the prevalence of people with chronic illness or disability who need some type of intermittent or long-term care will also increase. Most of the care responsibility will fall on relatives, such as spouses and adult children, and profoundly change their day-to-day lives. Family members cease to be just husband/wife/partner/significant other/son/daughter but take on the identity of "caregiver."

Family or informal caregiving is a stressful, life-consuming activity that often impacts the social, emotional, and financial health of the caregiver. Caregiver burden has been described as a 
negative reaction to the impact of providing care on caregivers' social, occupational, and personal roles.1 Studies of family caregivers suggest that stress and burden can affect their physical and mental health. Negative health outcomes such as depression 2 and overall poor health including a lowered immune system and higher blood pressure 3 have been reported. Family caregivers may also experience burnout, 4 which can cause early nursing home placement for the care recipient.5 Most alarming, family caregivers experience an increased mortality rate6 and are at a greater risk for abusing the care recipient7 as a consequence of stress and burden.

Various programs and interventions have been developed to assist family caregivers to cope with the demands of caregiving. These support services include assistance with caregiving or related tasks and emotional or educational support that is provided to family caregivers by health professionals and community service providers. Some examples of support services include information and referral, education, support groups, counseling, meal programs, or personal care services such as home health or adult day centers. These types of services often alleviate some of the stress and burden by providing family caregivers with the knowledge, skills, and confidence to be a family caregiver. They may also reduce tension by sharing the care responsibility or providing the family caregiver with respite. Many support services simply acknowledge the family caregiver's work and feelings around caregiving, which validates the family caregiver and helps him or her deal with difficult emotions such as grief, fear, resentment, anger, guilt, and helplessness.

Despite the multitude of available resources, family caregivers continually underutilize support services. Litwin and Attias-Donfut11 reported in their study of family caregivers that one-half received no help at all, about one-tenth received care from a household member, and one-third were helped by paid, formal caregivers from outside the household. Brodaty and colleagues 12 found that for family caregivers of people with Alzheimer's, one in 3 caregivers was not receiving any support services and one in 4 used only one service.

A key overarching reason why family caregivers do not utilize support services is that many people who perform the duties of caregiving do not necessarily self-identify as caregivers.13 In 2001, the American Association for Retired Persons (AARP) Caregiver Identification Study14 surveyed 4037 adults in order to better understand perception and identification of family members with the term caregiver as well as to establish incidence of caregiving and care-related activities. This study asked 2 questions to determine ways of identifying one's self as a caregiver. The first question directly asked the person whether she or he had been a caregiver in the past year and the second question indirectly asked about the person's participation by providing a detailed description of activities typically associated with caregiving. Of the sample, $44 \%$ selfidentified as a caregiver or admittedly participated in the described caregiver activities. Of particular interest, 15\% admitted to providing the kind of assistance described in the second question but did not self-identify as a caregiver in the first question. Since 2001, no new studies have addressed the prevalence of family caregivers who perform the traditional duties of a caregiver but do not necessarily self-identify as a caregiver. Nevertheless, the AARP study14 and a number of other studies 15,16 linked self-identification as a caregiver to the use of support services.

Identity - Theoretical Underpinnings 
Much attention has been given to the concept of identity in the past 20 years. Numerous disciplines and subfields have added to the literature on the definition and development of racial, religious, gender, national, and other identities. Identity is of particular interest because of its influence on behavior.17,18 According to Thoits and Virshup,19 people utilize socially meaningful categories to describe themselves, including sociodemographic characteristics (i.e., gender), social roles (i.e., husband, parent), social types (i.e., runner), or personality traits (i.e., funny, kind). These identifications form a set of identity standards based on the meanings and expectations associated with these categories that guide identity-relevant behaviors. Identity and identification of others is necessary to understand the world. In order to successfully "regulate and govern their lives, individuals need to develop a stable and meaningful identity structure, which enables them to maintain a sense of self-continuity over time and space and which provides a frame of reference for making decisions, problem-solving, and interpreting experience and self-relevant information."20, p.295

Identity development is a complex phenomenon that is, for the most part, socially constructed. Erik Erikson, the first theorist to explicitly focus on identity formation, believed that identity developed through the interaction among a person's "psychological and biological dispositions and one's social context."21,p.82 Identity formation has 2 dimensions - self and social. The first is reflexive in nature and based on a person's own narrative. The second occurs if that "self" identity is acknowledged and supported by others. People come to know who they are by interacting with others and knowing how others see them.22

Identity is not fixed and continues to develop and evolve over time.21 It is to be expected that life experience will cause identity to be examined, reconfigured, and changed.23 Banaji and Prentice 24 suggested that identity change takes place in response to major changes in role and situational demands. Major changes may be related to family life, like marriage or childbirth, or they can be related to accomplishments like completing school or retiring. Significant life changes cause a person to restructure his or her roles, which will often be associated with changes in identity. 25

Another theory to explain identity change is Hughes'26 "master status." Master status refers to a role that has become more important than any other label or role at that time. This role often shapes a person's entire life, overshadowing all other roles. For example, racial and ethnic identity is one of the most common master statuses reported in the literature.27 Master status has serious significance in identity renegotiation as a single role grows and becomes more dominant than any other role. Master status is referred to as master identity in contemporary research and has the same meaning.28 Despite the extensive literature on caregivers, understanding the transition to being a caregiver and the actual adjustment process for family members is limited. The concept of caregiver began as an operational term but is now a distinct identity with serious implications for those who perform the tasks but do not accept the role.

\section{Purpose}

The purpose of this literature review is to examine and summarize the literature related to the development of family caregiver identity. It will provide a comprehensive synthesis of previously published information as well as the theory and context for a future project to develop 
a tool that measures the extent to which a person identifies with the family caregiver role. Specifically, the following research question will be answered: What factors are related to the development of family caregiver identity?

\section{Methods}

A high-quality review using a systematic procedure was conducted with the purpose of understanding the development of family caregiver identity. The aim of the study was to locate valid and reliable literature that explored the development of caregiving identity; to identify major conceptual and theoretical foundations for caregiver identity development; and to report on the findings with regard to their contribution to a tool to measure caregiver identity. In order to do this, a comprehensive search strategy using keywords was adopted.

\section{Search Strategy}

The literature review involved an academic database search of keywords to identify literature that linked "caregiver" and "identity" within their title, abstract, or keywords (Table 1). A generic database search for the key terms caregiver (or alternative forms) and identity (or alternative forms), using appropriately selected search engines, was conducted. The engines included were Academic Search Complete, CINAHL Plus, PsycINFO, Ageline, ProQuest Central, and Medline. Sources of information included books, dissertations, journal articles, and other scholarly works. Furthermore, reference lists from the obtained articles were manually searched to obtain additional literature sources to review.

\begin{tabular}{|c|c|}
\hline Keyword & Operational Definitions \\
\hline \multirow[t]{3}{*}{ Family caregiver } & $\begin{array}{l}\text { A family caregiver is a type of informal caregiving. } \\
\text { An informal caregiver can be defined as anybody } \\
\text { who provides unpaid help to an unwell person. }{ }^{29}\end{array}$ \\
\hline & $\begin{array}{l}\text { The majority of informal caregivers are family } \\
\text { members such as spouses and adult children of the } \\
\text { care recipient. Thus, informal caregivers are often } \\
\text { referred to as family caregivers. The term caregiver }\end{array}$ \\
\hline & $\begin{array}{l}\text { is also referred to as carer or care provider in } \\
\text { the literature. }\end{array}$ \\
\hline Identity & $\begin{array}{l}\text { Identity is described by Burke } 25 \text { as "the self-meanings } \\
\text { that define who one is." } \text { (p.81) Alternative terms } \\
\text { for identity include self-concept, self-referent label, } \\
\text { identity status, or self-categorization. }\end{array}$ \\
\hline
\end{tabular}

Table 1. Keywords and Operational Definitions for Literature Review

\section{Inclusion Criteria}

The original years of review ranged from 1990 to 2014. This selection coincides with the 10 years prior to the AARP study14 on caregiver identity, which was the first large-scale study specifically examining caregiver identification and the present. The inclusion criteria for article selection encompassed all studies and articles from both refereed and nonrefereed literature sources determined by the author to be relevant to this literature review. Included literature had to involve information related to (1) influences on caregiver identity or (2) caregiver identity development. 


\section{Exclusion Criteria}

Literature was excluded if it did not contribute to answering the research question, was not in the English language, and did not explicitly focus on family caregivers of adults with a chronic disease. Furthermore, literature was excluded if it was not scholarly in nature, such as a newspaper or magazine article.

\section{Analysis and Theme Development}

The determination of major themes related to the development of family caregiving identity included a thorough and systematic content analysis of selected articles. During initial reading, certain words, phrases, sentences, and paragraphs were marked for significance and further review. This early stage of analysis would be considered open coding in grounded theory qualitative research because the method is seen as the "opening up" of the texts so that meanings and ideas are revealed.30 After reading through the articles again, precoding was done by "circling, highlighting, bolding, underlining, or coloring rich quotes or passages" that contribute to the research purpose and question.31, p.19 Once precodes were identified, a master list of formal codes was developed to outline categories and subcategories of information based on similar meanings or connotations. The articles were read for a third time with the intention of specifically examining categories and subcategories. The relationships between fragmented parts of categories and subcategories were then grouped into themes. Once themes were identified, articles were read again so that the themes could be compared. To ensure soundness and consistency, the articles were reviewed numerous times in regards to emerging themes.

\section{Limitations}

Although a systematic and procedural approach to reviewing the literature was followed, the possibility of selective reporting always exists. 32 It is likely that some important articles were overlooked. There is also no guarantee that the assessment or interpretation of the literature was appropriate. In addition, this review was not intended to be a meta-analysis, nor an evaluation of the quality of study design and conduct. Instead, the literature presented here includes information related to broad themes related to family caregiver identity and family caregiver identity development.

\section{Results}

The bulk of literature located was considered unrelated to this review (Figure 1). Ultimately, 34 sources were obtained to provide literature reference for this narrative review. Of the 34 sources, only 23 articles of variable quality specifically investigated or discussed the development of family caregiver identity. Five of the sources specifically dealt with linking caregiver selfidentification and support service use. Two were from the same authors and were different applications of their caregiver identity theory or reported similar findings. The remaining 4 briefly mentioned caregiver identity but did not substantially contribute to the understanding of caregiver identity development. 


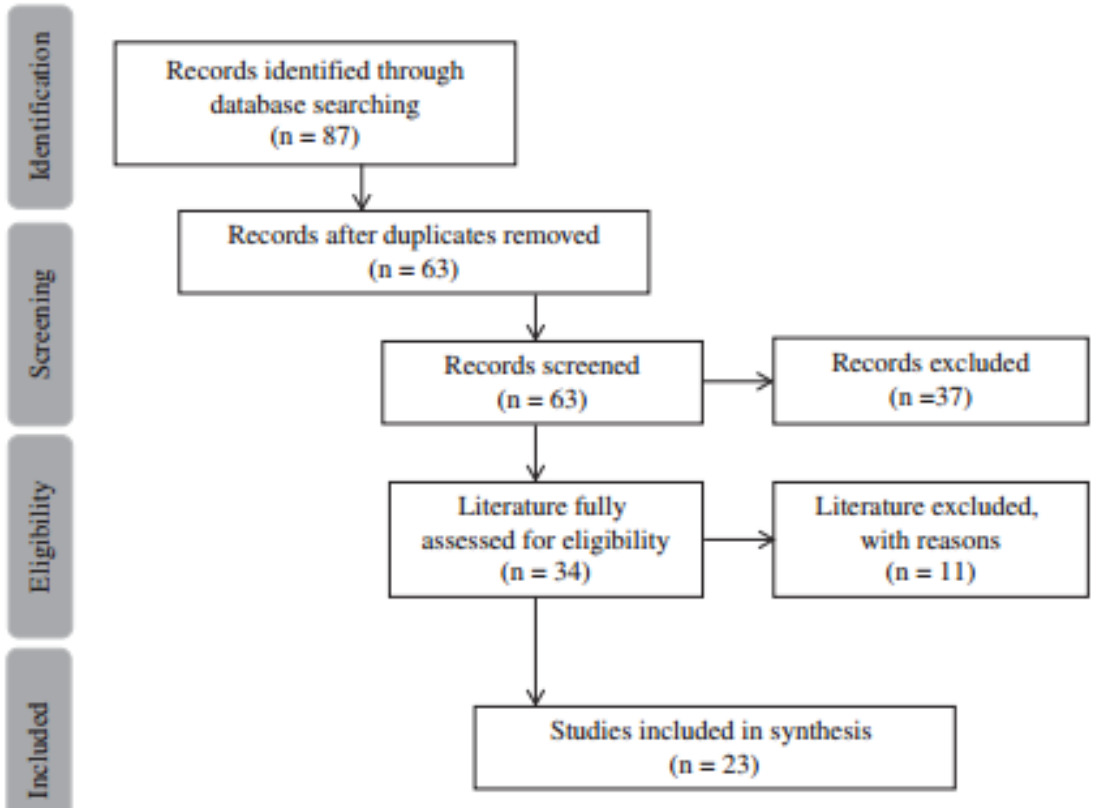

Figure 1 Flow diagram of systematic review process and results. Adapted from Moher et al. and the PRISMA Group.33

A variety of perspectives, methodologies, and theoretical lenses were used in the literature to examine the development of caregiver identity. Five major themes emerged from the sources of literature, all interrelated and concerning aspects of caregiving identity development. See Table 2 for the included literature, categorized by the author according to the major findings presented in them. It should be noted that some of the sources had multiple findings and could have been placed in several categories. The results of the literature review and final themes are described in the ensuing paragraphs. 


\begin{tabular}{|c|c|}
\hline Factor & Supporting Literature \\
\hline $\begin{array}{l}\text { Role engulfment and losing self } \\
\text { When the role of caregiver and } \\
\text { responsibilities of caring begin to } \\
\text { consume a person, leaving little time } \\
\text { for other activities and behaviors } \\
\text { that may have defined the person } \\
\text { previously. }\end{array}$ & $\begin{array}{l}\text { Miller et al. } \\
\text { Sherrell et al. } \\
\text { Heward et al. } \\
\text { O'Connor }^{34} \\
\text { Burton }^{37}\end{array}$ \\
\hline $\begin{array}{l}\text { Loss of shared identity } \\
\text { Changes to a person's dyadic identity } \\
\text { because the dyad is diminishing } \\
\text { or lost. }\end{array}$ & $\begin{array}{l}\text { Hasselkus and Murray } \\
\text { Coeling et al. } \\
\text { Hayes et al. } \\
\text { Adams } \\
\text { Orona }^{41}\end{array}$ \\
\hline $\begin{array}{l}\text { Family obligation and gender norming } \\
\text { A system of assumptions, beliefs, and } \\
\text { values created by a society that frame } \\
\text { how a family should respond to } \\
\text { a caregiving situation and who is } \\
\text { expected to be the caregiver, } \\
\text { especially females. }\end{array}$ & $\begin{array}{l}\text { Paoletti }^{45} \\
\text { Hughes et al. } \\
\text { Kirsi et al. } \\
\text { O'Connor }^{16}\end{array}$ \\
\hline $\begin{array}{l}\text { Extension of former role } \\
\text { Caregiving is seen as a normal and } \\
\text { natural part of being a spouse/partner } \\
\text { or child. }\end{array}$ & $\begin{array}{l}\text { Montgomery and Kosloski }{ }^{47} \\
\text { Goldsteen et al. }{ }^{49} \\
\text { Karner and Bobbitt-Zeher }{ }^{48} \\
\text { Henderson }^{15} \\
\text { Golden }^{50} \\
\text { Carpentier }^{51}\end{array}$ \\
\hline $\begin{array}{l}\text { Master identity } \\
\text { When the caregiver role becomes the } \\
\text { dominant identity, replacing or } \\
\text { overtaking any other important } \\
\text { identity, partly influenced by } \\
\text { other people. }\end{array}$ & $\begin{array}{l}\text { Skaff and Pearlin } \\
\text { Dickson et al. }^{53} \\
\text { Moore and Gillespie }\end{array}$ \\
\hline
\end{tabular}

Table 2 Factors and Supporting Literature Related to Caregiver Identity Development

Role Engulfment and Losing Self

Role engulfment and losing self occurs when the role of caregiver and responsibilities of caring begin to consume a person, leaving little time for other activities and behaviors that may have defined the person previously. The individual's identity gradually comes under pressure as the caregiver role intensifies. Individuals do not just gain a new identity as caregiver but see previous identities fade away or become less relevant because of caring responsibilities.

Heward et al.34 found in their study of partners of individuals with multiple sclerosis that identities were reshaped by the loss of former roles and the development of new roles.

Respondents previously defined themselves as homemakers, part of a parenting team, or breadwinners and were now struggling with "running the home independently and, in some cases, acting as sole parents and "carers" while also providing financially for the family."(p.27) This finding suggests that as the caregiver role intensifies, former identities began to erode.

O'Connor35 believes that initially caregiver identity is grounded within the bounds of the familial relationship, but gradual deterioration of their loved one prompts them to reconsider their identity. At first, most caregivers are too busy to "reflect upon their role"(p.168) but 
recognition that he or she has taken over leads to the notion that he or she is a caregiver. Similar to Heward and colleagues,34 caregiver identity emerges as the caregiver role intensifies.

In a case study involving a female adult child caring for her parents, Sherrell et al.36 briefly discussed the caregiver's "age-role" identity and how no longer seeing her "parents as protectors, but rather as needing protection, they (she) must shift their (her) own identity. ..."(p.387) This analysis of the caregiver's interview indicates that caring for one's parents can cause a shift in the way a person sees his or her parent, which can impact the caregiver's identity.

Furthermore, Burton37 found that when caregivers begin to care, they struggle with their own new role as well the role of social services and the person they care for. Their inexperience and the "cumulative effects of increasing isolation, additional responsibilities and the loss of the person's abilities ..."(p.500) make adjusting to their new role challenging. Many participants focused on "what they had given up to be a carer"(p.500) and wished to maintain the life they had together before caregiving.

In their qualitative study with family caregivers of elderly parents, Miller et al.38 found that there were 2 structures that factored into the development of the participants' caregiver identities. The first was the parent-child structure. The respondents discussed role reversal and having to "parent their parent." They drew upon "memories of their own childhood and of their experience in raising children in constructing their identities as caregivers."(p.36) The second was the competence structure. The respondents expressed a "had to be done" attitude regarding caregiving. For most of the respondents, they were the only ones competent enough to be the caregiver and do it right. They spoke of having to play multiple roles, including banker, physician, shopper, driver, chef, etc., to complete care tasks, often at the expense of their paying jobs. These 2 structures suggest that individuals perform a myriad of tasks that engulf them and often make them feel more like the parent (or caregiver) than the child.

\section{Loss of Shared Identity}

As mentioned previously, many caregivers have a prior relationship with the care recipient. A person may have an identity based on that relationship or being part of a couple (i.e., "us" or "we" rather than "I"). This shared identity is often referred to as dyadic identity. This identity cannot function or continue without the other person. For example, to be a daughter, you have to have a mother or father. If you lose one or both parents, what happens to your identity as a daughter? Caregiving often forces changes in well-established patterns of interactions that impact how that person sees him- or herself in that pair. Loss of shared identity consists of changes to a person's dyadic identity because the dyad is diminishing or lost.

Coeling et al.39 attempted to conceptualize a dyadic identity and how caregivers and care recipients negotiate the dyad's rules that influence how caregiving fits with their current relationship. This process involves joint decision making based on long-established patterns of negotiation between the caregiver and care recipient. Various factors, such as learning the rules, ease of negotiation, and the need for renegotiation effects how dyadic structuring occurs. The process and results of this negotiation lead "to a mutually accepted identity."(p.24) 
Shared identity emerged as a major theme in the interpretation of caregiver narratives in a study by Hasselkus and Murray.40 They proposed that chronic illness (in this study, dementia) "caused disruption in their (caregiver) lives and forced major changes in their daily routines and ways of viewing their selves."(p.16) Interruptions in former patterns of interaction and reciprocity between the caregiver and the care recipient caused changes in the "caregiver's biographical self that was embedded in the shared identity."(p.16)

Orona41 suggested that being a member of a caregiver-care recipient dyad is a core category in understanding identity. Caregivers question their shared identity when tremendous changes brought on my dementia occur to their loved one. Orona identified several themes related to identity loss, including social structure, reciprocity, and temporality. Social structure is related to the multiple roles a person has and how identity may be different in each situation. Eventually, caregiver becomes the primary role and can impact each of the other identities. Reciprocity pertains to the contribution that each person makes in the relationship. This occurrence maintains and transforms the other's identity. Eventually, a care recipient may no long be able to reciprocate. Orona specifically addressed temporality by discussing the shared history, memories, and biographies that accompany relationships. The loss of the person's ability to participate in these shared experiences leads to an identity transformation.

Hayes et al.42 examined identity changes in the care recipient due to dementia and how these changes alter how their spouses identify themselves within their marriage. Due to the loss of cognitive functioning, many spouses report diminished intimacy, feelings of closeness, and reciprocity. The changes in the person with dementia threaten their spouse's own sense of self. Wives are more likely than husbands to report that "perceived changes in impaired spouses' identity altered how they identified themselves in relation to their spouse, shifting from a wife and lover to a mother or constant provider."(p.57)

Adams 43 identified 4 forms of story within informal caregivers' accounts of caring for a loved one with dementia, including pre-onset stories, recognition stories, searching stories, and dependency stories. More than stories, these are memories with special significance that demonstrate a strong connection between the caregiver and care recipient. Pre-onset stories were references to who or what the person was like before they had dementia. Recognition stories were related to early symptoms of dementia and how the caregiver recognized their loved one had dementia. Search stories pertain to the caregiver's efforts to "find out what was happening to their relative."(p.247) Finally, dependency stories allow for the caregiver to describe the increasing dependency of their loved one. These stories allow for inference about the development of caregiver identity and suggest that the shared relationship between the dyad is a significant factor.

Family Obligation and Gender Norming

Family obligation and gender norming are rooted in societal expectations of role obligations and perceived moral expectations. Society has created a system of assumptions, beliefs, and values that frame how a family should respond to a caregiving situation and who is expected to be the caregiver. Females rather than males are often expected to take on the responsibility of caring because they are perceived as the more gentler and compassionate of the two genders. 
O'Connor16 found that the responsibility of providing care to a spouse or significant other is assumed and related to being a "good" husband/wife/partner. If anyone challenged this expectation, he or she would be perceived as unloving or selfish by society. For most participants, the belief was "so strong that it generally went without question; 'of course' one assumed responsibility for overseeing the care needs of one's spouse. ...'(p.218) This belief was particularly true for women, who O'Connor believes are socialized to care and to be concerned about the well-being of others.

Other people's expectations played a significant role in Hughes et al.'s44 findings on personal identity and caregiving. They stated, "Variability and fluidity in self-identification as a carer may be related to other people's expectations about whether one should assume the caring role.

..."(p.83) Participants in the study demonstrated that if they willingly chose to be the caregiver and the care recipient was grateful for this assistance, they often embraced the role and identity of caregiver. However, if the role of caregiver was forced upon them, participants often resisted the role and identity. Additionally, for many caregivers the role of caregiver was enforced by others or absorbed into existing roles that led to easily self-identifying as a caregiver.

From a feminist perspective, Paoletti45 proposed that caregiving is a gendered practice; furthermore, caregiving is a "central aspect of gender identification."(p.808) Caregiving develops in relation to pairs, such as father-daughter, husband-wife, etc., which is clearly related to the reason for taking up caregiving duties. Many of the participants constructed caregiving as a feminine practice. Caring is not something that the males of the family cannot do or will not do, but the expectation that they will does not exist. This finding suggests that caregiving is closely related to gender identity.

Gender was of particular interest to Kirsi et al.'s46 study of male caregivers caring for their spouses. Kirsi and colleagues examined "stories of himself as a caregiver and as a man."(p.167) Participants reported a masculine obligation to care for their unwell wives with references to wartime and having to perform domestic duties, a traditionally female task. These findings hint that perceptions of "female and male ways of caregiving"(p.159) exist.

\section{Extension of Former Role}

Similar to family obligation and dyadic identity, the extension of former role theme is related to societal expectations and relationships. Caregiving is seen as a normal and natural part of being a spouse/partner or child. In this situation, individuals do not feel obligated per se, but the act of caring is normalized and accepted in the current relationship.

Montgomery and Kosloski47 stated that over time, "caregivers not only change their behaviors, but they also change the way they see their role in relation to the care recipient - that is, their role identity."(p.136) They outlined this process by identifying 5 possible "phases of accommodation."(p.143) Phase 1 is the period of role onset and occurs when the caregiver begins performing caregiving activities. Caregiving is a small portion of their relationship. The caregiver is rarely has awareness of their caregiver identity. Phase 2 begins when the caregiver realizes that his or her caregiving activities are beyond the scope of the initial family role. Caregiving is approximately $25 \%$ of the relationship. Identification as a caregiver starts to 
develop. Phase 3 occurs when the caregiver realizes that his or her caregiving activities are significantly beyond the scope of the initial family role. Caregiving now accounts for approximately $50 \%$ of the role relationship. This shift begins a true identity negotiation as the caregiver struggles with his or her initial identity and the new caregiver identity. Phase 4 continues to see an increase in care needs and a solidification of the caregiver identity. Caregiving now dominates the role relationship. Phase 5 is reached when the caregiver turns over primary responsibility for care to formal care providers (i.e., nursing home placement). Caregiving retreats back to $25 \%$ of the relationship. The caregiver may retain his or her caregiver identity or shift back to his or her primary identity.

Karner and Bobbitt-Zeher48 described caregiving as a shift in identities and reconstructed relations. They suggested that when caregiving tasks are associated with their ongoing role as spouse or child, the individual may not identify oneself as a caregiver. When the care recipient is "unable to perform their previous role of spouse or parent, they can no longer meet the interactive expectation of their partner or child to maintain the relationship,"(p.13) and caregiver identity can develop.

Moreover, Goldsteen and colleagues49 provided a framework for caregiver identity development through normative expectations and ideas about responsibility. They tell the story of a woman who is the caregiver of her mother and her identity shift from daughter to caregiver. In the beginning she resists being labeled a caregiver but as the situation with her mother gets worse and professional caregivers are not of assistance, her identity as a daughter changes and she is redefined.

In her dissertation, Golden50 examined the construction of identity in a support group, emphasizing how group members "position themselves, how other group members respond to those position, and the implication of positions."(p.44) Support groups confirm or deny a caregiver's positioning of himself through the sharing and conversations that occur in open forums like a support group. Findings suggest that caregivers construct identity in relation to their spouses. Spouse and caregiver are simultaneously interacting identities - the identity of caregiver is rooted in the spousal relationship. In support groups, group members can be subjective spouses and objective caregivers.

Additionally, Henderson 15 proposed that care takes place within relationships. In particular, caregiving involves a "process of negotiation and re-negotiation between partners."(p.150) Unfortunately, the agreement between the caregiver and care recipient can be called into question when "... professionals assume that someone's partner is their carer.”(p.155) Caregiver may be an identity some aspire to be, but for others an identification of caregiver "bears no similarity to their own construction of their role within a partnership."(p.155) The findings suggest that the label of caregiver is negotiated between the couple and that the label is sometimes prematurely placed by professionals on the person without readiness or acceptance.

Previously held roles clearly played a part in caregiver identity development in Carpentier's51 case study on the relationship between identity and formal and informal care systems.

Carpentier51 found that "the caregiver plainly saw herself as the central person in her mother's life and she intended to maintain this relationship, which was an integral component of her 
identity."(p.47) The caregiver featured in this case study had a history of close family ties and little reliance on resources outside the family which led to a commitment to maintain "a sense of continuity" (p.47) for her mother. The caregiver believed that knowledge and awareness of life history was "essential to making appropriate decisions"(p.48) that could not be done if there was not a prior relationship between the caregiver and care recipient. This solidifies her role as her mother's primary care provider and her identity as a caregiver.

\section{Master Identity Develops}

As seen in role engulfment and losing self, caregivers are often consumed by their responsibilities. This engulfment can lead to the loss of other identities and the prevailing identity becoming caregiver that would fit with Hughes' 26 master status or master identity theory mentioned previously. Master identity develops when the caregiver role becomes the dominant identity, replacing or overtaking any other important identity. Fundamental to this theme is that in addition to caregiver naturally emerging as the dominate identity, others begin to recognize and refer to the person as a caregiver.

According to Skaff and Pearlin,52 caregiver identity develops as a result of the loss of self and role engulfment. In their study, “... caregivers essentially expressed the sense that the only identity left to them is that of caregiver."(p.658) In this context, caregiver self-identification is not so much a process of development but the result of "the main or sole surviving context for self-evaluation."(p.658)

Dickson et al.53 examined spousal caregivers' understandings of what it is to live with an individual with a spinal cord injury. Participants reported that "duties and responsibilities that they felt obliged to perform often prevented them from being able to engage in activities that they wanted or would choose to participate in,"(p.1112) such as taking a nap or getting a meal. The caregiver role claimed the vast majority of their time and left no time to partake in that activities that once defined his or her sense of self. Many of the participants stated that their only value was as a caregiver and that "assuming the role of partner caregiver, resulted in them becoming 'invisible' to other people - that their well-being became secondary to that of their injured partner."(p.1112) This statement indicates that the new role as caregiver has altered the way in which they as well as others perceive them.

Moore and Gillespie54 discussed "the caregiving bind," where caregivers conceal the demands and extent of caregiving, to protect the identity of the care recipient, which ends up undermining social processes that the caregiver needs to establish the caregiver identity. Participants who were caregivers would often downplay to others the care recipient's limitations in an effort to preserve the care recipient's personal identity. This would lead to family members, friends, and health professionals believing that the care recipient was fairly independent and the person providing care to be undeserving of the label caregiver. The findings suggest that the caregiver bind leads to delayed development of the caregiver identity because there is a lack of acknowledgement from others that the person providing care is indeed a caregiver.

\section{Discussion}


The aim of this literature review was to identify, examine, and summarize the literature related to the development of caregiver identity. The analysis identified 23 sources that contributed to the research question: What factors are related to the development of family caregiver identity? The literature indicated several themes related to the development of family caregiver identity, including role engulfment and losing self, loss of shared identity, family obligation and gender norming, extension of the former role, and development of a master identity.

It is not surprising that roles and responsibilities is a significant factor related to family caregiver identity development. Providing care to someone with a chronic condition can comprise a wide range of activities. Responsibilities can include assistance with activities of daily living, such as bathing, dressing, and eating, as well as instrumental activities of daily living, such as transportation, housework, grocery shopping, meal preparation, managing finances, or coordination of outside services.55 A person with dementia may require additional care and supervision because of symptoms of the condition, including a lack of judgment, communication difficulties, sleeplessness, and behavioral symptoms such as wandering or aggression. On average, caregivers spend 20.4 hours per week providing care.56 The sheer amount of responsibilities and time commitment leaves little time or energy for other activities that may shape a caregiver's identity. This contributes greatly to our understanding of master identity and provides a theoretical framework for how caregiver identity develops.

It is not unexpected that a shared identity and familial ties were contributing factors to caregiver identity development. As previously mentioned, the majority of informal caregivers are family members. Caregivers most often are aiding a parent or spouse with a chronic disease.56 An existing reciprocal relationship with established obligations and expectations as husband/wife or daughter/son is probable. Each participant has an understanding of who the other is and agreedupon patterns of interaction. Shared identity and familial ties are central to identity.

Given the just mentioned shared identity and familial ties, caregiving as a systematic process of identity change in which the caregiving role emerges out of an existing role relationship is also logical. The long-lasting and incurable nature of most chronic diseases contributes greatly to this factor. Caregiver identity slowly develops as the needs of the care recipient increase in quantity and intensity and the previous relationship becomes less familiar over time.

Most of the literature referenced that identity is socially constructed. Individuals may be unaware of the label but through interactions with others, they develop an awareness and eventual identity related to caregiving. McCall and Simmons57 believe that people seek legitimization of their identity. One's identity is constantly being changed and reevaluated based on interactions with other. Even in Henderson's 15 finding that prematurely placing the caregiver label on someone was distressing for some, the occurrence may prompt others to reconsider their identity and adopt the caregiver identity.

Theoretical Framework

Drawing upon the factors related to family caregiver identity found in the literature, a theoretical framework was created (Figure 2). The theoretical framework explains the key factors, concepts, or variables related to caregiver identity. The theoretical framework informed and guided the 
development of the Family Caregiver Identity Scale, a tool to measure the extent to which a person identifies with the family caregiver role.

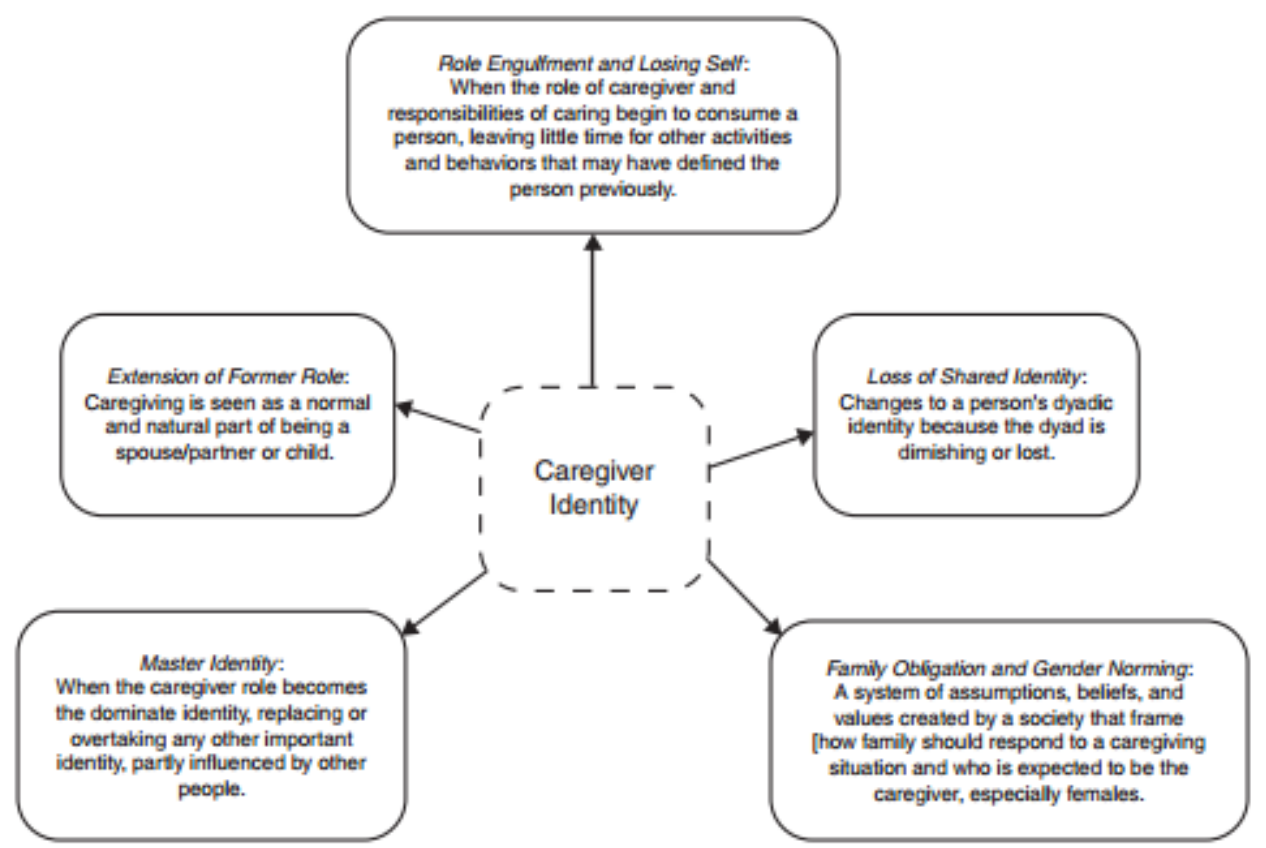

Figure 2 Theoretical framework to explain the key factors related to caregiver identity.

\section{Translation to Health Education Practice}

Understanding family caregiver identity has far-reaching implications for the health education field. The need for long-term care of those with chronic disease is rising and the number of family caregivers is expected to increase by $85 \%$ between 2000 and 2050.58 According to Biddle and colleagues, 17 identity is "among the more significant determinants of behaviors and deserve(s) an expanded research effort."(p.178) Furthermore, if caregiver identity continues to be rejected by those who technically occupy the role, "caregiving may continue to be hidden and potentially sources of help and support may remain underutilized."44, p.79

Health educators can address the underutilization of support services by family caregivers of those with chronic disease by considering the relationship between the responsibilities for Certified Health Education Specialists (CHES) 59 and caregiver identity. Specifically, the creation of an instrument to measure how strongly a person identifies with the caregiver role has the following implications for the 7 areas of responsibility60:

1. Assess individual and community needs for health education: A caregiver identity instrument could potentially allow CHES and other support service providers to screen individuals who perform the duties of caregiving to determine their immediate and longterm needs.

2. Plan health education strategies, interventions, and programs

a. Without an understanding and acceptance of the caregiver label, an individual will be blind to the community ready to offer their support. CHES and other support service providers could use the instrument as part of their health education programing. 
b. A caregiver identity instrument would allow CHES and other support services providers to identify caregivers who have accepted the label of caregiver to include them in developing strategies for intervention.15

3. Implement health education strategies, interventions, and programs: CHES and support service providers will need to understand caregiver identity to implement health education successfully. Caregivers will not use support services that they do not perceive as needed or useful because they do not see themselves in that role. Assisting caregivers in adjusting to their new role and identifying with the label may need to be the first step in implementing strategies, interventions, and programs aimed at assisting caregivers.

4. Conduct evaluation and research related to health education

a. Informal caregivers become more proactive and empowered about research and care for their loved one after they have assumed the caregiver identity. CHES and support service providers could be instrumental in providing education on what exactly is a caregiver and who qualifies for that label.

b. A caregiver identity instrument would offer a new avenue for health education evaluation and research related to caregivers.

5. Administer health education strategies, intervention, and programs: Funding for caregiver programming is minimal but steadily increasing as the country ages and more caregivers are needed. Innovative research focusing on caregiver identity and grounded in theory may offer a unique funding stream for health education programs.

6. Serve as a health education resource person: CHES and support service providers must reach out to informal caregivers who need information or support. Additionally, CHES and support service providers must partner with professionals from other fields to identify and refer individuals who provide care and may need support.13

7. Communicate and advocate for health and health education

a. CHES and support service providers must define caregivers broadly and often to be inclusive and increase the opportunity for caregivers to identify with that definition of who they are and what they do.13

b. CHES and support service providers can reduce "incongruence between what the caregiver is doing - his caregiving activities - and what the caregiver thinks he should be doing - that is, his 'identity standard"'61 through health education.

Underutilization of support services is currently considered an important but poorly understood issue.12,59 According to Carpentier and colleagues62:

Certain families manage to get organized, to mobilize resources, and to forge support ties with professional service providers. It is imperative to acquire a better understanding of the initial period, to identify the actors capable of playing important roles, and to gain a firmer grasp of the influence of attitudes and values likely to foster a more rapid acceptance of the disease and quicker access to and a more appropriate use of resources available in the community.(p.335)

Examining the influence on family caregiver identity offers direction for health educators and interventions aimed at increasing support service utilization by family caregivers. Understanding this identification process may be helpful in overcoming previous attempts by support service organizations to reach family caregivers. 


\section{References}

1. Given B, Wyatt G, Given C, et al. Burden and depression among caregivers of patients with cancer at the end-of-life. Oncol Nurs Forum. 2001;31:1105-1117.

2. Wright L, Hickey JV, Buckwalter KC, Hendrix SA, Kelechi T. Emotional and physical health of spouse caregivers of persons with Alzheimer's disease and stroke. J Adv Nurs. 1999;30:552-563.

3. Farran CJ, Loukissa D, Perraud S, Paun O. Alzheimer's disease caregiving information and skills. Part II: family caregiver issues and concerns. Res Nurs Health. 2004;27:40-51.

4. Yilmaz A, Turan E, Gundogar D. Predictors of burnout in the family caregivers of Alzheimer's disease: evidence from Turkey. Aust J Ageing. 2009;28:16-21.

5. Donaldson C, Tarrier N, Burns A. Determinants of carer stress and Alzheimer's disease. Int J Geriatr Psychiatry. 1998;13:248-256.

6. Schulz R, Beach SR. Caregiving as a risk factor for mortality: the Caregiver Health Effects Study. JAMA. 1999;282:2215-2219.

7. Schiamberg LB, Gans D. An ecological framework for contextual risk factors in elder abuse by adult children. J Elder Abuse Negl. 1999;1:79-103.

8. Dorfman LT, Berline KL, Holmes CA. Attitudes toward service use among wife caregivers of frail older veterans. Soc Work Health Care. 1998;27(4):39-64.

9. Strain L, Blandford A. Community based services for the taking but few takers: reasons for nonuse. J Appl Gerontol. 2002;21:220-235.

10. Winslow W. Family caregiver's experiences with community services: a qualitative analysis. Public Health Nurs. 2003;20:341-348.

11. Litwin H, Attias-Donfut C. The inter-relationship between formal and informal care: a study in France and Israel. Ageing Soc. 2009;29:71-91.

12. Brodaty H, Thompson C, Fine M. Why caregivers of people with dementia and memory loss don't use services. Int J Geriatr Psychiatry. 2005;20:537-546.

13. Dobrof J, Ebenstein H. Family caregiver self-identification: implications for healthcare and social service professionals. Generations. 2003;27(4):33-38.

14. American Association of Retired Persons. AARP Caregiver Identification Study. http://assets.aarp.org/rgcenter/post-import/caregiver.pdf. Published February 2001. Accessed March 2014.

15. Henderson J. "He's not my carer-he's my husband": personal and policy constructions of care in mental health. J Soc Work Pract. 2001;15(2):149-159.

16. O'Connor DL. Living with a memory-impaired spouse: (re)cognizing the experience. Can J Aging. 1999;18:211-235.

17. 17. Biddle BJ, Bank BJ, Anderson DS, et al. Social influence, self-referent identity labels, and behavior. Sociol Q. 1985;26(2):159-185.

18. Stets JE, Burke PJ. A sociological approach to self and identity. In: Leary MR, Tangney JP, eds. Handbook of Self and Identity. New York, NY: Guilford Press; 2003;128-152.

19. Thoits PA, Virshup LK. Me's and we's: forms and functions of social identity. In: Ashmore R, Jussim L, eds. Self and Identity. New York, NY: Oxford University Press; 1997;106-133.

20. Berzonsky MD, Cieciuch J, Duriez B, Soenens B. The how and what of identity formation: associations between identity styles and value orientations. Pers Individ Diff. 2011;50:295-299. 
21. Kroger J. Identity in late adulthood. In: Kroger J, ed. Identity Development: Adolescence Through Adulthood. 2nd ed. Thousand Oaks, CA: Sage Publishications; 2006;191-216.

22. Erikson E. Identity, Youth, and Crisis. New York, NY: W. W. Norton; 1968.

23. Cross SP, Markus H. Possible selves across the life span. Human Dev. 1991;34(4):230255.

24. Banaji MR, Prentice DA. The self in social contexts. Annu Rev Psychol. 1995;45:297332.

25. Burke PJ. Identity change. Soc Psychol Q. 2005;69:81-96.

26. Hughes EC. Dilemmas and contradictions of status. Am J Sociol. 1945;50:353-359.

27. Helms JE. The conceptualization of racial identity and other "racial" constructs. In: Trickett EJ, Watts RJ, Birman D, eds. Human Diversity: Perspectives on People in Context. San Francisco, CA: Jossey-Bass; 1994;285-311.

28. 28. Haworth-Hoeppner S, Maines D. A sociological account of the persistence of invalidated anorexic identities. Symb Interact. 2013;28:1-23.

29. Spillman BC, Black KJ. Staying the Course: Trends in Family Caregiving. Washington, DC: AARP Public Policy Institute; 2005.

30. Strauss A, Corbin J. Basics of Qualitative Research: Techniques and Procedures for Developing Grounded Theory. 2nd ed. Thousand Oaks, CA: Sage; 1998.

31. Saldana J. The Coding Manual for Qualitative Researchers. Los Angeles, CA: Sage; 2009.

32. Dickersin K. Publication bias: recognizing the problem, understanding its origins and scope, and preventing harm. In: Rothstein HR, Sutton AJ, Borenstein M, eds. Publication Bias in Meta-Analysis: Prevention, Assessment and Adjustments. Chichester, UK: John Wiley \& Sons, Ltd; 2005;11-34.

33. Moher D, Liberati A, Tetzlaff J, Altman DG, the PRISMA Group. Preferred Reporting Items for Systematic Reviews and Meta-Analyses: the PRISMA Statement. PLoS Med. 2009;6(6):e1000097. doi:10.1371/journal.pmed.100009.

34. Heward K, Gough B, Molineux M. Change of identity: the psychological and emotional impact of caring for someone with multiple sclerosis. Soc Care Neurodisability. 2011;2:21-32.

35. O'Connor DL. Self-identifying as a caregiver: exploring the positioning process. J Aging Stud. 2007;21(2):165-174.

36. Sherrell K, Buckwalter K, Morhardt D. Negotiating family relationships: dementia care as a midlife developmental task. Fam Soc. 2001;82:383-392.

37. Burton M. Grounding constructions of carers: exploring the experiences of carers through a grounded approach. Br J Soc Work. 2006;38:493-506.

38. Miller KI, Shoemaker MM, Willyard J, Addison P. Providing care for elderly parents: a structurational approach to family caregiver identity. J Fam Community. 2008;8:19-43.

39. Coeling HV, Biordi DL, Theis SL. Caregivers and care receivers. J Nurs Scholarsh. 2003;35:21-25.

40. Hasselkus BR, Murray BJ. Everyday occupation, well-being, and identity: the experience of caregivers in families with dementia. Am J Occup Ther. 2007;61:9-20.

41. Orona CJ. Temporality and identity loss due to Alzheimer's disease. Soc Sci Med. 1990;30:1247-1256.

42. Hayes J, Boylstein C, Zimmerman MK. Living and loving with dementia: negotiating spousal and caregiver identity through narrative. J Aging Stud. 2009;23:48-59. 
43. Adams T. Construction of identity in the accounts of informal carers for people with dementia. Educ Ageing. 2002;17:237-255.

44. Hughes N, Locock L, Ziebland S. Personal identity and the role of "carer" among relatives and friends of people with multiple schlerosis. Soc Sci Med. 2013;96(100):7885.

45. Paoletti I. Caring for older people: a gendered practice. Discourse \& Society. 2002;13:805-817.

46. Kirsi T, Hervonen A, Jylha M. "A man's gotta do what a man's gotta do": husbands as caregivers to their demented wives, a discourse analytic approach. J Aging Stud. 2000;14(2):153-169.

47. Montgomery RJV, Kosloski KD. Pathways to a caregiver identity and implications for support services. In: Talley RC, Montgomery RJV, RCI for Caregiving, eds. Caregiving Across the Life Span: Research, Practice, Policy. New York, NY: Springer; 2012;131156.

48. Karner TX, Bobbitt-Zeher D. Losing self: care work as negotiated order. Paper presented at: 99th Annual meeting of the American Sociological Association; August 2004; San Francisco, CA.

49. Goldsteen M, Abma T, Oeseburg B, Verkerk M, Verhey F, Widdershoven G. What is it to be a daughter? Identities under pressure in dementia care. Bioethics. 2007;21:1-12.

50. Golden MA. Coping and Caring: The Social Construction of Identity in a Support Group for Spouses of Persons With Dementia [dissertation]. Salt Lake City, UT: University of Utah; 2005.

51. Carpentier N. Caregiver identity as a useful concept for understanding the linkage between formal and informal care systems: a case study. Sociol Mind. 2012;2:41-49.

52. Skaff MM, Pearlin LI. Caregiving: role engulfment and the loss of self. Gerontologist. 1992;32:656-664.

53. Dickson A, O'Brien G, Ward R, Allan D, O'Carroll R. The impact of assuming the primary caregiver role following traumatic spinal cord injury: an interpretative phenomenological analysis of the spouse's experience. Psychol Health. 2010;25:11011120.

54. Moore H, Gillespie A. The caregiving bind: concealing the demand of informal care can undermine the caregiving identity. Soc Sci Med. 2014;116:102-109.

55. Davis KL, Marin DB, Kane R, et al. The Caregiver Activity Survey (CAS): development and validation of a new measure for caregivers of persons with Alzheimer's disease. Int $\mathrm{J}$ Geriatr Psychiatry. 1997;12:978-988.

56. National Alliance for Caregiving \& AARP. Caregiving in the US. http://www.caregiving.org/data/Caregiving_in_the_US_2009_full_report.pdf. Published November 2009. Accessed March 2014.

57. McCall G, Simmons J. Identities and Interactions. New York, NY: Free Press; 1978.

58. Department of Health and Human Services \& Assistant Secretary for Planning and Evaluation. The Future Supply of Long-term Care Workers in Relation to the Aging Baby Boom Generation. Washington, DC: Department of Health and Human Services \& Assistant Secretary for Planning and Evaluation. http://aspe.hhs.gov/daltcp/reports/ltcwork.pdf. Published 2003. Accessed August 2003.

59. National Commission for Health Education Credentialing. A Compentency-Based Framework for Health Education Specialists_2010. Whitehall, PA: National 
Commission for Health Education Credentialing, Society for Public Health Education, and American Association for Health Education; 2010.

60. Montgomery RJV, Kosloski K. Caregiving as a process of changing identity: implications for caregiver support. Generations. 2009;33:47-53.

61. Robinson K, Buckwalter K, Reed D. Differences between dementia caregivers who are users and nonusers of community services. Public Health Nurs. 2013;30:501-510.

62. Carpentier N, Ducharme F, Kergoat MJ, Bergman H. Social representations of barriers to care early in the careers of caregivers of persons with Alzheimer's disease. Res Aging. 2008;30:334-357. 